\title{
A mídia versus a leitura significativa
}

\author{
Carolina Nogueira Rodrigues* \\ Joselina das Dores Silva** \\ Keite Francisco Pereira de Souza*** \\ Sidney Sousa Silva****
}

\begin{abstract}
Resumo
O presente artigo investiga a função cultural e social da escola diante de uma mídia popularizada que tem interferido no processo de aquisição da leitura e escrita. Para isso, realizou-se uma pesquisa bibliográfica acerca do processo de letramento, dos meios de comunicação e da falta de preparo do sistema educacional perante esses recursos tecnológicos. Como aporte teórico, utilizou-se Magda Soares, Frank Smith, Ezequiel Teodoro Silva, Moran, Foucambert, Adorno e Walter Benjamin, importantes autores para a discussão sobre leitura e os veículos de comunicação. Assim, conclui-se que a escola deve utilizar de forma consciente a cultura imposta pela mídia como um instrumento pedagógico educativo para formar leitores críticos.
\end{abstract}

Palavras-chave: leitura, escola, mídia, cultura.

\section{The media versus significant reading}

\begin{abstract}
This paper analyzes the cultural and social role of the school in the face of a popularized media which has interfered in the process of learning to read and write. To do so, a literature search on the literacy process, the media and the lack of preparation on the part of the educational system in the context of such technological resources, was carried out. Authors versed in analysis of reading and the media, such as Magda Soares, Frank Smith, Ezekiel Teodoro Silva, Moran, Foucambert, Adorno and Walter Benjamin served as a theoretical background. It was concluded that the school should use the culture imposed by the media as an educational learning tool in a discerning manner to form critical readers.
\end{abstract}

Keywords: reading, school, media, culture.

* Professora da Rede Municipal de Goiânia. Especialista em Alfabetização. E-mail: carolinanr09@ gmail.com

** Professora da Rede Municipal de Goiânia. Especialista em Alfabetização. E-mail: josy123lua@ gmail.com

*** Professora da Rede Municipal de Goiânia. Especialista em Alfabetização. E-mail: keitefrancisco@ yahoo.com.br

**** Professor do Instituto Federal de Educação, Ciência e Tecnologia Goiano, Campus Morrinhos. Mestre em Letras e Linguística pela Universidade Federal de Goiás, UFG. E-mail: sidneysilvabrasil@hotmail.com 
Diante das preocupaçóes que envolvem o cotidiano dos professores em relação à aquisição da leitura, especialmente neste momento em que os meios de comunicação estáo cada vez mais desenvolvidos e popularizados, buscamos compreender os impactos que a mídia tem gerado na formação inicial do leitor. Para isso, utilizaremos a expressão leitura significativa a partir do conceito definido por Smith:

A leitura significativa proporciona não somente as pistas essenciais e o feedback necessário para aprender a ler, mas proporciona também o seu próprio reforço. Aprender a ler é uma atividade que dá prazer. O que estimula as crianças a ler e, com isso, a aprender a ler, não é alguma promessa de satisfação no futuro, ou uma "recompensa extrínseca" como elogios, boas notas, um tratamento especial ou evitar alguma punição, mas ser capaz de ler. (1999, p. 53)

Segundo Smith (2002), com o incremento dos meios de comunicação, ocorreu uma claríssima mudança na situação e na função da leitura na atualidade. Nos países ricos, esse incremento náo colaborou para uma crise na leitura, ao contrário, as indústrias editoriais têm aumentado sua oferta, o que não tem acontecido nos países pobres, onde a crise tem afetado os âmbitos internos e externos à escola.

Nas escolas, temos observado o uso constante de vários meios de comunicação, tais como filmes, revistas, jornais, músicas, internet, cartazes e outros, para incrementar o trabalho pedagógico. Todavia, no Brasil, esses meios têm desempenhado um efeito contrário, por colaborar com a crise pela qual passa a leitura significativa na formação dos estudantes.

Conforme aponta Smith (2002, p. 36), a "leitura é fundamental para os que estão interessados no desenvolvimento das crianças e dos jovens e para todos os que desejam contribuir para o crescimento do país". Esta reflexão é relevante, pois o Brasil é mais um país pobre que tem sofrido com esta situação, e ela, ao interferir na formação do indivíduo, concomitantemente, interfere na própria construção da soberania nacional.

\section{A leitura no processo do letramento}

De acordo com Martins (1994), a leitura sempre foi um privilégio das classes dominantes. Saber ler e escrever, desde os gregos antigos e os romanos, já significava possuir bases de uma educação adequada para a vida. "Educação essa que visava não só ao desenvolvimento das capacidades 
intelectuais e espirituais, como das aptidões físicas, possibilitando ao cidadão integrar-se efetivamente a sociedade" (MARTINS, 1994, p. 22). Apesar do avanço da civilização, pouca coisa mudou, pois o analfabetismo ainda persiste mesmo nos países ricos. Entretanto, a conquista da leitura pelas classes populares significou a apropriação de um instrumento indispensável não só para a elaboração de sua cultura, como também para alterar a condição social dos indivíduos.

A leitura é uma das habilidades mais importantes e fundamentais que podem ser desenvolvidas pelo ser humano. A partir da leitura de mundo, o sujeito pode compreender a realidade em que ele está inserido e chegar a importantes conclusóes sobre o seu mundo e os aspectos que o compóem.

Anteriormente, o termo leitura consistia no simples reconhecimento de letras, sílabas e palavras. No entanto, percebe-se hoje que o conceito de leitura não é tão limitado como se pensava. Pelo contrário, é muito amplo. Por isso, em nosso estudo, encontramos diversos autores que abordam o tema.

Até pouco tempo atrás, ler consistia em decodificar símbolos gráficos, reconhecer as palavras e pronunciá-las bem. Com a modernidade, surgiu a exigência de haver um leitor eficiente que fosse capaz de atribuir significação ao texto relacionando-o à sua experiência pessoal. Isso fica claro nos Parâmetros Curriculares Nacionais do Ensino Fundamental de Língua Portuguesa:

A leitura é um processo no qual o leitor realiza um trabalho ativo de compreensão e interpretação do texto, a partir de seus objetivos, de seu conhecimento sobre o assunto, sobre o autor, de tudo o que sabe sobre a linguagem etc. Não se trata de extrair informação, decodificando letra por letra, palavra por palavra. (BRASIL, 1998a, p. 69)

Entendemos, então, que ler vai muito além da simples decodificação; ler é a capacidade de o leitor estabelecer relaçóes com outros textos ou de formular inferências.

Para Foucambert (1984, p. 5), "ler significa ser questionado pelo mundo e por si mesmo, [...] significa construir uma resposta que integra parte das novas informaçôes ao que já se é". É utilizar leituras anteriores para refletir e se tornar "um sujeito ativo que processa o texto e lhe proporciona seus conhecimentos, experiências e esquemas prévios" como defende Solé (1998, p. 18). Ou simplesmente, como diz Silva (1998), ler é compreender. 
Segundo Magda Soares, estudiosa do processo de alfabetização e letramento, a leitura não é um ato solitário, "é interaçâo verbal entre indivíduos e indivíduos socialmente determinados" (2002a, p. 47). E, ao considerar a leitura enquanto tecnologia, Soares diz ser "um conjunto de habilidades linguísticas e psicológicas, que se estendem desde a habilidade de decodificar palavras escritas até a capacidade de compreender textos escritos" (2002a, p. 68-69), ou seja, o processo de leitura leva o sujeito a refletir e adquirir a capacidade de julgar.

Foucambert também afirma que não existe leitura "se não existir uma expectativa, uma pergunta, uma questão, antes da interação com o texto". Diante dessa expectativa criada, o autor expóe que "ler é ser questionado pelo mundo e por nós mesmos, é saber que certas respostas podem ser encontradas no escrito; é poder ter acesso a esse escrito; é construir uma resposta que integre uma parte das informaçóes novas e tudo o que já sabemos" (p. 6).

Qualquer texto é sempre produzido em um determinado momento histórico-social. Do mesmo modo, a leitura decorre de um conjunto de conhecimentos e informaçóes disponíveis no momento em que a leitura se realiza, o qual determina diferentes formas de ver o mundo. Ler de forma competente significa compreender que a leitura é também um ato individual e único, que ocorre através de "pensamentos sobre pensamentos, vivências sobre vivências, palavras sobre palavras, textos sobre textos", um constante diálogo (BAKHTIN, 2006, p. 307).

Todavia, não deve ser um diálogo ingênuo, o leitor precisa perceber e julgar, descobrir as representaçóes da realidade e situá-las em uma determinada visão de totalidade. A dificuldade de julgamento, como afirma Moran (2011), faz com que muitas pessoas obtenham muitos dados e não consigam colocá-los na visão de totalidade. É o caso das informações veiculadas pelos jornais que, se permanecem soltas e não fazem sentido para quem as lê, acabam por ser esquecidas imediatamente.

Desse modo, ler com compreensão inclui, além da compreensão superficial de textos, a capacidade de ler o que está implícito. Smith (1999) descreve que a referência à produção de textos implica focalizar a leitura e a escrita como processos interativos centrados no significado. Este enfoque atual modifica a ideia tradicional que considerava separadamente a leitura como um processo de decodificação, e a escrita como um processo de codificação. A partir desta ênfase no processo de aquisição da leitura e da escrita, faremos uma distinção entre ser alfabetizado e letrado de acordo com Soares: 


\begin{abstract}
A diferença está na extensão e na qualidade do domínio da leitura e escrita. Uma pessoa alfabetizada conhece o código alfabético, domina as relações grafofônicas, em outras palavras, sabe que sons as letras representam, é capaz de ler palavras e textos simples mas não necessariamente é usuário da leitura e da escrita na vida social. Pessoas alfabetizadas podem, eventualmente, ter pouca ou nenhuma familiaridade com a escrita dos jornais, livros, revistas, documentos, e muitos outros tipos de textos; podem também encontrar dificuldades para se expressarem por escrito. Letrado, no sentido em que estamos usando esse termo, é alguém que se apropriou suficientemente da escrita e da leitura a ponto de usá-las com desenvoltura, com propriedade, para dar conta de suas atribuiçóes sociais e profissionais. (SOARES apud CARVALHO, 2008, p. 66)
\end{abstract}

Sendo assim, letramento é o "estado ou a condição em que vivem e interagem indivíduos ou grupos sociais letrados" que não só decifram signos linguísticos, mas que participam de eventos em que a escrita é parte integrante da interação entre as pessoas (SOARES, 2002b, p. 145).

Para compreendermos melhor o processo de alfabetização, faremos um retrospecto sobre essa situação no Brasil. Desse modo, é preciso relembrar o analfabetismo como uma problemática que se iniciou na colonização brasileira, em que existia o monopólio da língua pelos jesuítas e aristocratas, estendendo-se do Império até a República. Esse cenário de alto índice de analfabetismo necessitou ser transformado em razão da falta de mão de obra com o mínimo de escolarização. Por isso, a partir de 1940, com a implementação da industrialização no país, a educação de adultos se constituiu em um tema de política educacional. Todavia, "essas iniciativas náo resolveram o problema de expandir efetivamente a alfabetização. Talvez por se constituírem em políticas fragmentadas que não colocaram a alfabetização como um projeto de democratização social e efetivo" (BARBOSA, 1990, p. 27).

Esse processo de alfabetização ocorreu de forma global, sendo que parte das naçóes do mundo conseguiu concretizar o projeto de forma generalizada, superando os limites das sociedades de tradição oral. Por um lado, as que alcançaram esse intento formaram sujeitos alfabetizados, porém não se descobriram leitores, mas meramente decodificadores do sistema linguístico, e incapazes de se atentarem para um ser defensor e possuidor de um censo crítico. Por outro lado, as naçóes que fracassaram neste processo viram-se imersas na pobreza, na fome, nas doenças e na marginalização social (BARBOSA, 1990). 
Desse modo, a partir dos altos índices de analfabetismo no Brasil, buscou-se uma posição para enfrentar o não domínio da leitura nas práticas cotidianas. Surge, então, o letramento, no qual o sujeito passa de alfabetizado para letrado, torna-se capaz de apropriar-se da escrita, fazendo com que esta se torne parte de sua vida como meio de expressão e comunicação. Por alfabetização e letramento adotamos a concepção de Carvalho (2008), pois afirma que a primeira consiste em "ensinar o código alfabético", já a segunda "é familiarizar o aprendiz com os diversos usos sociais da leitura e escrita".

Porém, a habilidade de compreensão não surge de forma natural, precisa ser exercitada e estendida, mesmo antes de a criança ter adquirido o sistema de escrita, ou seja, na fase inicial da alfabetizaçấo. Esta compreensão da criança é a meta principal do ensino da leitura, tendo como ponto de vista o letramento.

Segundo Smith (1999), a perspectiva de ver a importância da leitura, por meio das funçóes que pode cumprir, permite ao educador e a todos os que têm a ver com o desenvolvimento de um ser humano vincular a atividade de ler com as necessidades da pessoa. Assim, evita-se que a leitura se limite a uma simples habilidade mecânica, que tende a se extinguir por falta de aplicabilidade e consegue que seja vista como uma habilidade relacionada com os mais importantes aspectos da vida pessoal e de relação com o mundo.

Todo esse processo voltado à funcionalidade é o que faz a diferença no ensino de leitura na sala de aula, e é onde deve ser empregado para que haja ligação e sentido, pois é a partir daí que o aluno começa a ter gosto pela leitura e, consequentemente, uma boa produçáo textual.

Concluímos, por fim, que ler é mais do que uma simples decodificação, é muito mais que a própria compreensão; saber ler é compreender o que foi lido, é interpretar o sentido do que foi lido e criticar essas informaçóes de maneira que possa transferi-las para o seu cotidiano, fazendo análises críticas e dando opiniốes pessoais, traçando paralelos entre o que aprendeu com a leitura, com sua vida.

\section{Os meios de comunicaçáo envolvidos no processo da leitura}

A partir das definiçóes de filósofos como Adorno e Horkheimer, entendemos cultura de massa como o produto de uma atividade relacionada à estrutura econômica e ideológica a serviço do modo de produção capi- 
talista, que tem como função oprimir as demais culturas genuinamente autodeterminantes em detrimento da valorização dos gostos culturais de massa (SANTANA, 2010).

Os veículos de comunicação de massa servem para disseminar o conteúdo da cultura de massa. Essa expressão foi substituída posteriormente por indústria cultural, que é aquela criada com o objetivo de alcançar a massa popular, ou seja, a maioria da população, transcendendo toda e qualquer distinção de natureza social, étnica, etária, sexual ou psíquica (SANTANA, 2010).

Até algum tempo, os principais veículos de comunicação eram o cinema, o rádio e a televisão; hoje, podemos incluir a internet com o "Youtube", as "redes sociais" e outros adereços. Além desses veículos, temos também que incluir as revistas de fofocas, os jornais em que as matérias vêm todas mastigadas e outros veículos impressos para a comunicação de massas que se dedicam, em sua maioria, a homogeneizar os padróes de cultura.

Outra importante contribuição que utilizamos como alicerce para este artigo é a definição de cultura de massa ou indústria cultural elaborada pelo pensador francês Edgar Morin, que a apresenta como um produto padronizado, pronto para o consumo. Segundo o autor, esse tipo de cultura "é hipnotizante, entorpecente e indutiva" (MORIN apud SANTANA, 2010, p. 1).

O termo indústria cultural cunhado pelos teóricos da Escola de Frankfurt, tais como Walter Benjamin, compreende a obra de arte como mais uma mercadoria dentro do sistema capitalista. Benjamin acreditou que as obras de arte que alcançavam apenas uma pequena parcela da sociedade, com o advento das tecnologias avançadas nos meios de propaganda e comunicação, poderiam ser democratizadas, estendendo-se ao restante da população. Porém, as empresas que ficaram encarregadas de divulgar as obras apenas visavam ao lucro, a preocupação centrava-se em como vendê-las para as grandes massas. Sendo assim, era necessário que a arte se transformasse em algo leve, de fácil compreensão, que não necessitasse despertar a consciência crítica do seu público, ficando a cargo da cultura de massas o serviço de enaltecer a realidade e não propor a transformá-la. Já as obras que desafiavam o conhecimento se restringiam às produçôes eruditas.

Ao contrário do que Benjamin esperava, a cultura e as obras de pensamento náo foram democratizadas, e sim massificadas, ou seja, o que era considerado um bem cultural raro e caro se voltou aos privilegiados 
que podiam ter acesso; e as obras baratas e comuns ficaram voltadas às grandes massas. Dessa forma, a indústria cultural criou uma segregação cultural, em que, por um lado, há uma elite culta e, por outro, uma massa inculta. A definição do termo massa usado aqui é de Marilena Chauí que considera massa "um agregado sem forma, sem rosto, sem identidade e sem pleno direito à cultura" (2000, p. 423). Não bastasse esse prejuízo ao conhecimento, a indústria cultural falseia a realidade, na medida em que cria uma ilusão de que as escolhas são livres e de que tudo está ao alcance de todos, sem distinçáo social, racial e de gênero. Isso pode ser observado pelo exemplo que Chauí apresenta quanto às informaçóes divulgadas nos jornais:

Se compararmos, numa manhã, cinco ou seis jornais, perceberemos que o mesmo mundo - este no qual todos vivemos - transforma-se em cinco ou seis mundos diferentes ou mesmo opostos, pois um mesmo acontecimento recebe cinco ou seis tratamentos diversos em função do leitor que a empresa jornalística pretende atingir. A indústria cultural vende cultura. Para vendê-la, deve seduzir e agradar o consumidor. Para seduzi-lo e agradá-lo, não pode chocá-lo, provocá-lo, fazê-lo pensar, fazêlo ter informaçóes novas que o perturbem, mas deve devolver-lhe, com nova aparência, o que ele já sabe, já viu, já fez. (CHAUÍ, 2000, p. 423)

As empresas de produção artística também passaram a modificar as criaçóes populares e eruditas na medida em que elas começaram a ser interessantes ao público. Ao se apropriarem dessas produçóes, as empresas modificaram o teor genuinamente popular, e impregnaram nessas obras, antes críticas e criativas, um caráter modista e vazio de conhecimento, para serem facilmente comercializadas. $\mathrm{O}$ mais grave dessa situação é que essa induistria cultural atingiu também as produçóes de pensamento, extirpando delas tudo o que convergia à inovação, criação e crítica. $\mathrm{O}$ resultado disso foi o crescimento da produção e a comercializaçấo de livros de autoajuda e os de caráter pseudocientífico, assim como novelas e filmes que em nada favorecem o desenvolvimento de um senso estético. As obras do pensamento se reduziram à disseminação de ideias que são rapidamente perdidas e em nada contribuem com o conhecimento, a reflexão, sensibilidade, imaginação e inteligência.

Quanto aos veículos ou os meios de comunicação, estes são pertencentes à indústria cultural não pelo que são, mas porque são utilizados para este fim. Conforme Ribeiro (2007), a televisão brasileira intoxica diariamente os telespectadores com programas de conteúdo duvidoso. Os 
cinemas exibem conteúdos apenas relacionados aos Estados Unidos. Nas rádios, dominadas por rocks estrangeiros, programas evangélicos e gospel, a música brasileira é um produto raro certamente porque o Brasil é um lugar exótico e distante, cujos músicos só fazem sucesso na Europa e nos EUA.

Por isso, a questão central não está nos veículos, mas sim no uso dessas tecnologias, pois elas estâo nas mãos das classes dominantes, que detêm maior poder aquisitivo. São elas as donas das poderosas empresas multimídias e dos conglomerados privados que reproduzem e difundem bens culturais de acordo com o objetivo do consumo estético massificado. Os pensadores da Escola de Frankfurt foram os primeiros a compreender que, a partir daí, a família, a escola e mesmo a religiáo passaram a perder a influência sobre as empresas de comunicação; as que ainda existem são poucas e de restrito alcance (RIBEIRO, 2007).

Por mais que aparentemente esse tipo de cultura se apresente como algo apolítico, segundo os frankfurtianos, ela representa uma forma de controle social, responsável também (náo defendemos como o único) pela crise da vida política de nossas sociedades. Para Habermas, a crescente apatia ou o desinteresse da população para com a ação política, senão a própria vida democrática, é correlata à destruição da cultura como processo de formação libertador e de liberaçáo de potenciais cognitivos que têm lugar na era de sua conversão em mercadoria (HABERMAS apud RIBEIRO, 2007).

As teses frankfurtianas são vigentes, ainda que precisem ser atualizadas, pois realmente a indústria cultural, como bem colocada, conserva e dissemina as marcas das violências e da exploração a que o povo tem sido submetido ao longo de sua história, como nos apresenta Ribeiro:

A linguagem rebaixada, o menosprezo da inteligência e a promoção de nossos piores instintos, senão da brutalidade e estupidez, que encontramos em tantas expressóes da mídia, sem dúvida se devem ao fato de que há muitas pessoas sensíveis a esse tipo de estímulo, mas, e isso é o que importa, tal fato não é algo natural nem, também, algo criado pela comunicação. (RIBEIRO, 2007, p. 1)

Dessa forma, o que pretendemos elucidar com este artigo é que os meios de comunicação podem servir também como um benefício às massas se usados de forma a incentivar a criatividade, levar a questionamentos, a aguçar a curiosidade, a crítica e disseminar informaçôes de interesses genuinamente populares. Isso é totalmente possível, mesmo que inicialmente 
seja de pouca expressão em relação ao gigante aparato midiático que serve aos interesses do capitalismo.

Ribeiro (2007) nos apresenta essa possibilidade a partir das contradiçóes expostas por Walter Benjamin e Siegfried Kracauer, pensadores frankfurtianos, também criadores da pesquisa crítica em relação à comunicação. Eles defenderam que da mesma forma que o capitalismo criou as armas que irão derrubá-lo, ou seja, os proletários, eles criaram as condiçóes para uma democratização da cultura, uma vez que se socializou a distribuição em massa de discos, filmes e impressos. Esses pensadores demonstraram assim que

as experiências soviéticas feitas com o cinema, rádio e artes gráficas em seguida à revoluçâo levaram-nos a entender que as tecnologias de comunicação em surgimento estavam promovendo uma transformação no modo de produção e consumo da arte. Os privilégios culturais que durante tanto tempo a burguesia havia usufruído estavam em vias de ser derrubados, bastando apenas que as massas tomassem o controle dos meios de produçăo. (RIBEIRO, 2007, p. 1)

Adorno, outro teórico, manteve essa polêmica com Benjamin e Kracauer, pois ele dizia que essa democratização não passava de uma aleivosia, e que isso somente seria possível mediante uma transformação que permitisse que esses meios passassem ao controle das massas, e que, enquanto estes estiverem colocados a serviço da indústria cultural, essa demanda será impraticável (RIBEIRO, 2007).

Apesar do cenário um tanto dramático em relação ao uso dos meios de comunicação pelas grandes empresas midiáticas, devemos rediscutir essa utilização dentro das escolas. A partir de estudos de materiais produzidos e divulgados, mesmo que de forma restrita, pelo Ministério da Educação (MEC) sobre formação de professores, o uso de diferentes linguagens na sala de aula tem contribuído para encontrarmos um rumo mais adequado e possível para a sua democratização, antes mesmo que o povo tome o controle desses meios de comunicação.

Vale ressaltar aqui a importância da preparaçáo de educadores e de alunos para lidarem com este aparato tecnológico que está inserido em nossa vida. Uma das questóes centrais para se trabalhar de forma alternativa os meios de comunicação é estimular os estudantes a procurar e selecionar informaçóes. Essa tarefa está mais concentrada nas mãos dos professores que 
precisam, em primeiro lugar, ter objetivos e as competências que desejam alcançar com o uso desses meios, ou seja, os objetivos relacionados à Educaçáo. Dois caminhos que encontramos para enfrentar esse desafio estáo relacionados ao conhecimento e à construção do Projeto Político-Pedagógico da escola e à construção de projetos interdisciplinares de trabalho (BRASIL, 1998b). Por conseguinte, se queremos algo democrático, a escola que desejamos trabalhar precisa refletir isso, deve estar afinada com os interesses da populaçáo, com as exigências da comunidade, deve propiciar uma real participação de todos na solução dos problemas da sociedade.

Esses recursos tecnológicos interferem no ensino e aprendizagem, uma vez que trazem novas formas de ler, escrever, pensar e agir. Portanto, a introdução e a utilizaçáo desses novos recursos demandam mudanças na organização educacional e no currículo. Quanto ao aspecto pedagógico, o professor deve ser preparado para lidar com novas situaçóes de aprendizado, como nos aponta as orientaçóes do MEC:

Assim, o professor é preparado em situaçôes de aprendizagem que lhe propiciem atuar como mediador e promotor do processo de aprendizagem, segundo a zona de desenvolvimento proximal ZPD, de Vigotsky, promovendo a reflexão, a depuração e a construçáo do conhecimento. Nesse ambiente, o aluno é o sujeito da aprendizagem significativa porque lhe é dada a liberdade de trabalhar um conhecimento que esteja em sintonia com os seus interesses e necessidades. (BRASIL, 1998b, p. 69)

Precisamos trazer para as escolas o que os estudantes vivem fora dela para que eles reflitam sobre o que leem em outdoors, jornais, TV, letras de músicas, filmes etc., pois o que constatamos é que, ao ler os textos que circulam na sala de aula, os alunos sentem muita dificuldade em atribuir significados a eles. Concordamos com Menezes et al. (2002) quando afirma que ler é uma atividade que demanda questionamentos, diálogos e busca de respostas. Assim, ao aproveitar os interesses dos alunos e suas experiências sociais, a leitura poderá adquirir sentido.

Menezes et al. (2002) elaborou uma seleção de trabalhos com diversos meios de comunicação para procurar construir o significado para a leitura, porém, na sua seleção, ela desconsiderou a televisão e deu prioridade para o que os alunos reconhecessem nesse meio e também nos anúncios os receptores e as técnicas de manipulação. Ela propôs o trabalho com materiais de circulação social, como os jornais ou telejornais. 
O trabalho sugerido com a TV parte do princípio de que não devemos negar sua existência em quase todos os lares e, portanto, sua grande influência na vida das pessoas, disseminando hábitos, valores e cultura. Por isso, analisar algumas características da TV em sala de aula é importante: o seu aspecto monológico, pois com a programação da TV náo se discute; a adaptação tevê-sociedade, já que com os anos ela adentrou os lares e solucionou problemas como, por exemplo, deixar a criança assistindo à TV enquanto a mãe trabalha; a autoridade e liberdade em risco, "como faz uma família que deseja educar seus filhos fora das regras veiculadas pela TV?”; e, por fim, a crença nos meios de comunicaçáo, porque acreditar em tudo o que a TV ou o Rádio dizem pode gerar problemas; por exemplo:

Em 1938, Orson Welles leu, como se fosse uma notícia, trechos do romance $A$ guerra dos mundos, de H. G. Wells sobre a invasão de marcianos a Nova Iorque, o que provocou pânico nos Estados Unidos. Orson Welles contou com um fator importante: a crença de que o rádio noticiava a verdade. Se náo houvesse essa relaçáo de confiança, não teria havido pânico. (MENEZES et al., 2002, p. 25)

Daí a importância de alertar nossos alunos para o poder da influência desses meios; devemos mesmo é ter uma posição mais crítica, curiosa e independente diante da TV, do rádio, dos anúncios em geral, e da internet, por exemplo. Do mesmo modo, existem também as revistas dirigidas a meninos e meninas, com o objetivo somente do consumo de jogos, roupas, de que comer, formas de ser e de pensar. "O sistema capitalista neoliberal não pode pretender formar cidadãos. Investe na proliferação de consumidores. Dá-lhes propaganda, mas sem consciência. Por isso, o brasileiro ignora o que come. Nem as escolas educam para formar consumidores responsáveis" (BETTO, 1999 apud MENEZES et al., 2002, p. 134). Ou ainda,

tudo se banaliza, a ponto de ocorrer uma inversão em nosso enfoque: danem-se os direitos coletivos, as causas sociais, os valores e os ideais. O que importa é o chicote da mascarada, a privacidade da dançarina do Tchan, a filha da rainha dos baixinhos, o féretro da princesa que enterra a nossa ilusão de que a vida, para nobres e ricos, é sempre bela e feliz. (p. 133) 
Sobre a falta de leitura e/ou desinformação dos jovens, a pesquisa $O$ jovem e a mídia realizada em sete capitais do país, com enfoque em jovens das classes A, B, C e D, mostra a realidade dos jovens em nosso país:

O jovem de 12 a 20 anos está cada vez mais desinformado porque, progressivamente, lê menos, escuta menos rádio e assiste mais à televisão, porém, dá preferência, nessa ordem, a filmes, programas de esporte, novelas e, só então, a telejornais. [...] Sobre o hábito de leitura, 36\% disseram que nunca leem livros; $12 \%$ que quase nunca; $36 \%$ que às vezes; e apenas $16 \%$ o fazem com frequência. Sobre a leitura de jornais, $25 \%$ disseram nunca ler; $15 \%$ quase nunca; $45 \%$ às vezes e $15 \%$ sempre. (MENEZES et al., 2002, p. 3)

Kramer (2010) demonstrou, através de uma pesquisa, que existe uma grande diferença entre os professores atuais e os que lecionavam entre as décadas de 1920, 1930 e 1940, pois os professores dessas décadas percebiam uma intrínseca relação entre ser professor, ler e escrever. Para estes não havia como imaginar um professor que não fosse um leitor ou escritor. Os que atuaram nas décadas de 1940, 1950 e 1960 enfatizaram o papel da escola onde estudaram, pois tinham professores que eram poetas, romancistas e contistas.

O cenário atual é bastante complexo, pois os professores, em sua grande maioria, não são leitores nem escritores, e mais, além disso, não gostam mesmo desta prática. E é claro que essa situação está relacionada ao uso alienador dos meios de comunicação que desde há tempos vem acomodando não só as crianças e os jovens, mas também os adultos que preferem, diante da correria da vida turbulenta que levam, espreguiçarem-se diante da TV e ver tudo de forma mais mastigada e entorpecente possível. Essa geração não conseguiu adquirir uma saudável relação com a leitura e a escrita, pois o contato com essa prática nessas últimas décadas, na maioria dos casos, se restringiu a uma análise gramatical de textos literários ou a interpretaçôes rasas de textos - seja de qual gênero textual for - em que o leitor não interpreta o que fica implícito, não resolve problemas e não consegue ver significado na leitura.

Para uma possível mudança nesse quadro, não basta condenar o professor que não gosta de ler e escrever ou o aluno que se espelha nele, a questão-chave está no problema do sistema de ensino que apenas cobra resultados objetivos sobre a formação de nossos alunos e, consequentemente, 
a "competência" dos professores responsáveis por eles. Náo se analisa a situação deteriorada de trabalho dos professores. Por isso, como afirma Kramer (2010), é preciso que se defenda o direito de todos os professores a condiçóes salariais e de trabalho dignas, formação permanente, além de avanço na carreira, e experiências reais de leitura e escrita viabilizadas por uma política cultural que promova sua formação enquanto leitor crítico de textos e da própria sociedade em que vive.

\section{A falta de conhecimento perante esses meios}

Como afirma Moran (2011), os meios de comunicação na escola podem ajudar o professor em suas práticas pedagógicas:

Os meios de comunicaçáo desempenham um papel pedagógico relevante - náo absoluto - já bastante pesquisado, com dois momentos que podemos diferenciar grosso modo: o da pedagogia aberta, do entretenimento, do preenchimento do lazer como a atividade principal, e um segundo momento, quando os meios se propóem transmitir uma forma de organização do saber: programas mais sistemáticos, com conteúdos organizados em etapas ou dentro de um processo pedagógico definido, como um telecurso. (MORAN, 2011, p. 14)

Em contrapartida, numa sociedade do consumo, é necessário que haja uma leitura crítica mediante as informaçóes midiáticas apresentadas, visão que traga uma consciência de autonomia para o sujeito; dessa forma, "ler é o processo de passar da consciência ingênua, fragmentada, sincrética para uma visão crítica, totalizante, englobadora” (MORAN, 2011, p. 32). Como afirma Silva (1998), em relação à realidade educacional do Brasil, a facilitação da aprendizagem eficiente da leitura é um dos principais recursos que o professor dispóe para combater a massificação galopante, executada sobretudo pela televisão.

Como nem sempre é possível a mediação da família para com a criança, a escola fica responsável pela educação do sujeito para uma formação crítica a respeito da mídia. Dessa forma, "a missão da escola é capacitar seus alunos a fazerem da TV que eles veem todos os dias um uso crítico e ativo, isto é, inteligente" (BELLONI, 1991, p. 42).

Aproveitando a linguagem atraente que a mídia oferece aos educandos, o professor pode adequá-la a muitos conteúdos com o propósito de 
fomentar possibilidades de trabalho conjunto entre Mídia e Educação "ao introduzir noçóes, conceitos, teorias e conhecimentos concretos ou abstratos, que fazem parte dos currículos escolares, integrantes dos projetos político-pedagógicos das escolas brasileiras" (INFÂNCIA \& CONSUMO, 2009, p. 124).

Acerca da possibilidade de trabalhar a utilização da mídia na prática docente, verifica-se que, em países ricos, este recurso desenvolveu ainda mais o processo de aquisição da leitura, como afirma Smith:

Nos países desenvolvidos, os novos meios incrementam a leitura, nos países menos desenvolvidos, ela entra em crise. Nos primeiros, as indústrias editoriais têm cada vez mais elevado o número de pessoas que dedicam uma ou mais horas por dia à leitura; os impressos abrangem uma maior quantidade e variedade de temas. (1999, p. 35)

Vale dizer que a televisão também é um meio de transmissão da cultura, mas que tem apresentado uma programação de forma não sistemática e justaposta. Como exemplo, citamos um documentário histórico que, após sua transmissão, pode vir seguido de desenhos animados, telenovelas ou notícias, e durante a sua transmissão sempre é interrompido por anúncios comerciais. Portanto, em comparação à leitura, especialmente a do livro, esta oferece uma vantagem, pois na maior parte das vezes, apresenta uma sequência articulada do começo ao fim (SMITH, 1999, p. 37).

Um importante papel do professor é o de estimular o desenvolvimento da leitura e da escrita. Apesar de algumas crianças terem o gosto pela leitura sem ter sido promovido pelo professor, elas são a minoria, e já foi comprovado por pesquisas que esse gosto está intimamente ligado à orientação e ao incentivo dos pais. Isso porque o professor, depois dos pais, tem o papel principal e mais importante no desenvolvimento de hábitos e habilidades de leitura dos alunos. No entanto, o educador não deve ser autoritário a ponto de escolher sozinho o que seus alunos devem ou não ler, pois é importante considerar a diversidade dentro da sala de aula, os diversos gostos e as opinióes dos alunos, os quais devem ser valorizados, como afirma Ferraz (2007), a valorização da oralidade da criança e sua cultura fora da escola não deve ser encarada como uma subcultura. Então, para despertar o gosto pela leitura nos alunos, eles também podem escolher o que ler e, nesse caso, contar com a orientação do professor. 
Deve-se aumentar a autoestima da criança elogiando todos os progressos, até os aparentemente mais insignificantes. Isso para formar um ambiente favorável à leitura e à escrita na escola, especialmente quando há desigualdades sociais.

É importante variar os gêneros textuais ofertados às crianças, como textos em prosa ou verso, matérias de jornal, revistas infantis, textos informativos, receitas, manuais etc.

Algo também instigador é falar sobre o livro que a criança vai ler. Esse meio aguça a sua curiosidade em saber como a história vai acabar. Já ao final da leitura, é fundamental conversar com ela sobre o que leu, solicitando, por exemplo, que faça um paralelo com algum exemplo do seu cotidiano ou com outros livros que the foram familiar na leitura.

Visitas regulares à biblioteca também podem contribuir para estimular a leitura, pois a criança aprende a escolher e localizar o livro que lhe agrada, pode visitar seçóes especiais para crianças com vídeos e brinquedos e também pesquisar algum assunto solicitado em trabalhos escolares.

Contudo, todo esse processo não deve ser forçado, deve haver um interesse por parte da criança, para que seja prazeroso e não obrigatório.

É partindo deste trabalho, em que a escrita e a leitura tenham uma função social e interativa, que deve ser desenvolvida a alfabetização, em uma premissa voltada para o letramento.

Como já dissemos, é papel da escola, do professor, desenvolver habilidades de leitura, escrita e o gosto por ler. De acordo com Silva,

ninguém aprende a gostar de livros apenas ouvindo falar de livros ou vendo-os de longe, trancafiados numa prateleira - é necessário que a criança pegue e manipule o ingrediente "livro"; leia o que está escrito dentro dele para sentir o gosto e verificar se essa atitude tem ou poderá ter aplicação prática em seu contexto de vida. (SILVA, 1998, p. 55)

Não existem "receitas prontas" para o professor preparar bons leitores, mas uma maneira de ele despertar este gosto pela leitura é ler diariamente, na sala de aula, para os alunos. Dessa forma, o livro ainda continua a ser o veículo mais importante para a criação, transmissão e transformação da cultura, contribuindo para levar a criança a ter um pensamento crítico sobre o que lê e também sobre os meios com os quais ela interage. 
Smith (1999) nos mostra a importância do educador e de todos os que têm a ver com o desenvolvimento de um ser humano para vincular a atividade de ler com as necessidades da pessoa. Assim, evita-se que a leitura se desenvolva como uma simples habilidade mecânica que tende a se extinguir por falta de aplicabilidade e consegue-se que seja vista como uma habilidade relacionada com os mais importantes aspectos da vida pessoal e de interação com o mundo.

\section{Consideraçóes finais}

Morin defende que a indústria cultural é ludibriante, tendo em vista que é "introduzida no ser humano de tal forma, que se torna quase inevitável o seu consumo, principalmente se a massa não tem o seu olhar e a sua sensibilidade educados de forma apropriada, e o acesso indispensável à multiplicidade cultural e pedagógica" (MORIN apud SANTANA, 2010). Com base nessas afirmaçóes, acreditamos que é possível resistir a essa cultura impositiva com a utilização consciente de instrumentos pedagógicos educativos. Desse modo, fica clara a necessidade da formação de professores conscientes de seu papel na sociedade para inibir os impactos causados pelos meios de comunicação na formação de alunos leitores.

A leitura realmente está presente em todos os lugares. E para que ela ocorra de fato, precisamos de espaços não para as instruções de métodos e técnicas, precisamos que esses locais apresentem programas de formação cultural, em que a leitura e a escrita sejam experiências significativas.

A escola brasileira, segundo Kramer (2010, p. 189), tem perdido "seu sentido cultural, sua função social, seu importante papel enquanto instância de humanização, na medida em que não oferece condiçóes objetivas para o exercício da leitura, para o estudo, para a prática da escrita”. Assim, na escola, o aluno não pode aprender a não gostar de ler, é necessário entendermos que o gosto pela leitura é historicamente construído como tudo na vida.

Para finalizar todo esse debate, ou melhor, essa defesa do direito ao conhecimento dentro de nossas escolas, desde os anos iniciais, apresentamos este profundo apelo feito por Kramer a esse respeito:

Garantir o acesso à leitura e à escrita é direito de cidadania. A escola tem um papel importante a desempenhar na concretização desse direito, contribuindo na construçáo do conhecimento de crianças e adultos 
e ajudando-os a nunca esquecer a história, a sempre rememorar o esquecido, para que se torne possível - mais do que nunca - mudar a história. Para isso, ler a história é crucial. Por isso, escrever e reescrever os textos é essencial. Ler, escrever e reescrever os textos e a história, enquanto sujeitos da história que somos, tecendo - cada qual - os fios desta trama, neste ou em outros cursos [...]. (KRAMER, 2010, p. 18)

Por isso mesmo, é possível ao professor fazer renascer esse gosto dentro da escola, ao valorizar a contação de histórias; ao rememorar a história vivida; com o gosto de mostrar, de ler para o outro o que se escreveu; ao ler histórias em vez de sempre substituí-las por filmes; ao usar a internet para procurar textos, poesias, letras de música para serem socializadas na sala e para que se produza mais sem medo de errar. Qualquer modalidade de expressão, de invenção e de criação humana pode e deve ser aliada às práticas reais de leitura e escrita como ampliação da experiência cultural.

\section{Referências}

BAKHTIN, Mikhail. Estética da criação verbal. Tradução de Paulo Bezerra. 4. ed. São Paulo: Martins Fontes, 2006.

BARBOSA, José Juvêncio. Alfabetização e leitura. São Paulo: Cortez, 1990.

BELLONI, Maria Luiza. Educação para a mídia: missão urgente da escola. Comunicação e Sociedade. Revista de Estudos de Comunicação, v. 10, n. 17, ago. p. 33-45, 1991.

BRASIL. Parâmetros Curriculares Nacionais: Terceiro e Quarto Ciclos do Ensino Fundamental: Língua Portuguesa. Secretaria de Educação Fundamental. Brasília: MEC/SEF, 1998a.

BRASIL. Ministério da Educação. Salto para o futuro: TV e informática na Educação/Secretaria de Educação à Distância. Brasília: Ministério da Educação e do Desporto, SEED, 1998b. (Série de Estudos. Educação à Distância, ISSN 1516-2079, v. 3).

CARVALHO, Marlene. Alfabetizar e letrar: um diálogo entre a teoria e a prática. 5. ed. Petrópolis, RJ: Vozes, 2008.

CHAUÍ, Marilena. Indústria cultural e cultura de massa. Convite à Filosofia. São Paulo: Ática, 2000. Disponível em: <http://www.ins.gob.pe/ 
repositorioaps/0/0/jer/maestria_2012/MARILENA\%20CHAUI\%20-\%20 convite $\% 20 \mathrm{a} \% 20$ filosofia.pdf $>$. Acesso em: 17 jul. 2012.

FERRAZ, Joana Schiliam. Letramento e paralisia cerebral. Programa de Desenvolvimento Educacional, Curitiba, 2007. Disponível em: <http:// www.diaadiaeducacao.pr.gov.br/portals/pde/arquivos/516-2.pdf>. Acesso em: 15 out. 2011.

FOUCAMBERT, J. A leitura em questão. Porto Alegre: Artes Médicas, 1984. INFÂNCIA \& CONSUMO. Estudos no campo da comunicação. Coordenado por Veet Vivarta. Brasília: ANDI/Instituto Alana, 2009. 160 p. ISBN: 97885-99118-18-4. Disponível em: <http://serv01.informacao.andi.org.br/101fb149_120c3b05921_-7ffd.pdf>. Acesso em: 15 out. 2011.

KRAMER, Sônia. Alfabetização, leitura e escrita: formação de professores em curso. São Paulo: Ática, 2010.

LUFT, Celso Pedro. Dicionário de Língua Portuguesa. 13. ed. São Paulo: Ática, 1998.

MARTINS, Maria Helena. O que é leitura. Brasília: Brasiliense, 1994. Disponível em: <http://www.4shared.com/document/t5aeFFC0/O_que leitura_-_Maria_Helena_html>. Acesso em: 4 nov. 2011.

MENEZES, Gilda; TOSHIMITSU, Thaís; MARCONDES, Beatriz. Como usar outras linguagens na sala de aula. 3. ed. São Paulo: Contexto, 2002.

MORAN, José Manuel. Educação, comunicação e meios de comunicação. 2011. Disponível em: <http://www.crmariocovas.sp.gov.br/pdf/c_ ideias_09_013_a_017.pdf>. Acesso em: 15 out. 2011.

RIBEIRO, Fabio de Oliveira. Cultura, cultura de massas e etnologia. Observatório da imprensa. 423. ed. 2007. Disponível em: <http://www. observatoriodaimprensa.com.br/news/view/cultura_cultura_de_massas_e_ etnologia>. Acesso em: 10 out. 2011.

SANTANA, Ana Lucia. Cultura de massa, 2010. Disponível em: <http:// www.infoescola.com/sociedade/cultura-de-massa/>. Acesso em: 10 out. 2011.

SILVA, Ezequiel Theodoro. Elementos de pedagogia da leitura. São Paulo: Martins Fontes, 1998. 
194 Polyphonía, v. 23/1, jan./jul. 2012

SMITH, Frank. Encontrando sentido na leitura. Porto Alegre: Artes Médicas Sul, 1999.

SMITH, Frank. Situação da leitura em nivel internacional e local. São Paulo: Andres Bello, 2002.

SOARES, Magda. Novas práticas de leitura e escrita: letramento na Cibercultura. Educ. Soc., Campinas, v. 23, n. 81, p. 143-160, dez. 2002b. Disponível em: <http://www.scielo.br/pdf/es/v23n81/13935.pdf>. Acesso em: 10 out. 2011.

SOARES, Magda. Letramento: um tema em três gêneros. 2. ed. Belo Horizonte: Autêntica, 2002c.

SOLÉ, Isabel. Estratégias de leitura. 6. ed. Porto Alegre: Artmed, 1998.

Recebido em: 7 maio 2012

Aceito em: 18 set. 2012 